\author{
Marrit A. Tuinman \\ Harald J. Hoekstra \\ Dirk Th. Sleijfer \\ Joke Fleer \\ Damon J. Vidrine \\ Ellen R. Gritz
}

Josette E. H. M. Hoekstra-Weebers

\section{Testicular cancer: a longitudinal pilot study on stress response symptoms and quality of life in couples before and after chemotherapy}

Received: 23 March 2006

Accepted: 22 June 2006

Published online: 31 August 2006

(C) Springer-Verlag 2006

\author{
J. E. H. M. Hoekstra-Weebers \\ Comprehensive Cancer Center \\ North-Netherlands, \\ P.O. Box 330 \\ Groningen, $9700 \mathrm{AH}$, The Netherlands
}

social functioning over the year and no changes in physical functioning or mental health. No relationships between patients and partners' functioning were found. One year after diagnosis, QoL of patients and partners was similar to that of reference groups, and patients even reported better physical functioning than the reference group. SRS of patients and partners were negatively related at $\mathrm{T} 1$, and patients and partners' social functioning were positively related at T2. Conclusions: According to stress response levels, the period before the start of chemotherapy was most stressful for couples. Adjustment patterns differ between testicular cancer patients and their partners with patients reporting lowered QoL after completion of chemotherapy. QoL of couples returned to normal levels 1 year after diagnosis. The effect of disseminated testicular cancer on the QoL of patients and their partners seems to be temporary. A minority may need clinical attention for severe SRS.

Keywords Testicular cancer. Chemotherapy $\cdot$ Partners $\cdot$ Stress response symptoms - Quality of life

\section{Introduction}

Testicular cancer is a rare disease, although it is the most common tumor in men aged 20-35 years. About 500 new cases are diagnosed each year in The Netherlands [1]. Testicular cancer is distinguished into seminomas and nonseminomas, and each type accounts for about half of the total. Half of the men with nonseminoma are diagnosed 
with disseminated disease that is treated with chemotherapy [2]. Since the introduction of cisplatin-based chemotherapy in the late 1970 s, up to $80 \%$ of the patients with disseminated disease can be cured [3-5].

Chemotherapy for testicular cancer has several acute physical side effects like nausea, fatigue, and neuropathy [6]. On a psychological level, patients receiving chemotherapy have been found to report anxiety, depression, and distress [7-10]. The partners of testicular cancer patients receiving chemotherapy may encounter adverse sequelae as well. Partners have to struggle with the fear of potentially losing their significant other. Partners are the primary source of information for family members and friends while their husbands are admitted to the hospital. In addition to this social task, partners often take on the caregiver role between chemotherapy cycles. Caregiving for cancer patients was found to negatively impact a caregiver's physical and mental health [11-13].

The impact of testicular cancer on younger couples might differ from the impact on couples who face cancer at an older age. The young couples confronted with testicular cancer might not have been together for a substantial period of time. This can make the relationship more vulnerable to the stressors induced by major life events. Earlier studies have shown that relationships of shorter duration are more sensitive to disruption after a testicular cancer diagnosis $[14,15]$, although another study did not find such a connection [16]. Also, couples are confronted with possible treatment-related infertility and sexual difficulties at a time in life where partners are often focused on starting a family. Couples may face several individual and dyadic stressors after the diagnosis of testicular cancer, leading to the experience of distress and lowered quality of life (QoL). This is particularly true when chemotherapy is part of the treatment protocol, as it is a more demanding treatment modality than surgery alone in the case of testicular cancer.

Several prospective studies focused on dyadic adjustment and functioning from cancer diagnosis in a variety of sites, up to $11 / 2$ years later [17-20]. Although both patients and partners were reported to suffer from distress, levels of distress did not necessarily correspond within couples. Different patterns of distress and adjustment were found to be associated with gender and health status. Some studies reported that female partners were most vulnerable because they reported higher levels of distress than female and male patients and male partners [20-22].

One pilot study examined the course of distress and QoL in testicular cancer patients before, during, and after chemotherapy (complete data on ten patients). Patients reported highest levels of distress shortly before the start of chemotherapy. Distress and anxiety decreased over time [23]. Another recent prospective study on a large group of testicular cancer patients receiving chemotherapy focused on global QoL during the first 2 years after diagnosis. A considerable impairment in global QoL was found after 3 months. However, after 2 years $36 \%$ of patients reported improved functioning compared to baseline [24]. At the University Medical Center Groningen (UMCG) in The Netherlands, a tertiairy referral center for patients with testicular cancer, and at the University of Texas M. D. Anderson Cancer Center, USA considerable institutional research was done into epidemiology, short- and long-term medical, and sexual outcomes of testicular cancer [25-28]. These cross-sectional and retrospective studies were done on QoL of testicular survivors [29], their partners [30], and marital and sexual satisfaction [16, 31-33]. We chose to expand these findings by performing a prospective study, and the findings of Trask and Fossa by including partners in our prospective study. Patterns of stress response symptoms (SRS) and QoL of patients and partners were examined at three time points during the first year. SRS can occur after a range of traumatic events, including cancer. They involve intrusive thoughts and avoidance of thoughts and situations that remind them of the event, and are often studied in cancer patients [34]. Goals of the present study were: (1) to explore differences and relationships between patients and partners' SRS and QoL and to relate those to relationship aspects (duration and presence of children); (2) to examine change over time in SRS and QoL in patients and partners; (3) to relate earlier levels of SRS and QoL in patients and partners to later levels; and (4) to examine differences in QoL of patients and partners with that of a reference group of men and women.

\section{Materials and methods}

\section{Procedure and participants}

All patients diagnosed with a disseminated nonseminomatous testicular tumor who consecutively visited the UMCG in The Netherlands for treatment between April 2001 and March 2004 and who were married or cohabiting were approached for this study. Only patients who received chemotherapy and had a steady relationship $(n=30)$ could be included in this study. Other inclusion criteria were age over 18 years at study entry, sufficient command of the Dutch language, no previous treatment for cancer, and absence of a psychiatric history. The study was introduced to the patients and their partners after orchiectomy (removal of the affected testicle) was performed. Couples received a questionnaire at the following three time points: after orchiectomy but before the start of chemotherapy (T1), immediately after completion of chemotherapy, which is approximately 3 months after T1 (T2), and 1 year after T1 (T3). The patients received four cycles of cisplatin, etoposide, and bleomycin with a 3-week interval between each cycle. Couples received a letter with information about the objectives of the study, an informed consent form, the questionnaires, and a prepaid return envelope. Thirty of the 70 patients diagnosed during the above-mentioned time period appeared to meet all of the 
inclusion criteria. They and their partners were approached to participate in the study. Of the eligible 30 couples, 21 participated (70\%). Two couples did not complete all three measurement times, therefore, only 19 couples provided complete data. The study was approved by the Medical Ethics Committee of the UMCG.

\section{Measurements}

Sociodemographics: Data on the following sociodemographic variables were collected at T1: age, educational level, employment status, presence of children, and duration of the relationship. Highest educational level completed was measured on a seven-point scale: primary school [1], and lower vocational [2], lower secondary [3], middle secondary [4], high secondary [5], higher vocational degrees [6], and advanced university [7]. Employment status could be indicated as employed for wages, housekeeping, student, unemployed, unable to work, or retired.

SRS were measured with the Impact of Event Scale (IES) $[35,36]$. This scale (15 items) makes an inventory of the extent to which a subject is currently occupied with an event by measuring intrusion (intrusively experienced ideas, images, feelings, or bad dreams about the event; 7 items) and avoidance of unpleasant feelings or memories of the event (8 items), resulting in a total score of SRS. Patients and partners rated the frequency of SRS with respect to his cancer during the preceding 7 days. Examples of items include: "Any reminder brings back feelings about it" (intrusion) and "I try to banish it from my memory." The IES is a valid instrument for measuring cancer-related SRS $[37,38]$. With this questionnaire, information was obtained about the degree to which confrontation with testicular cancer was influencing the current daily life of the respondent. Higher scores indicate more SRS. The Dutch version of the IES indicates a total score of more than 26 as severe SRS, for which psychological help is recommended. Reliability of this scale was good for patients (Cronbach's alpha for the different measurement times ranged from 0.82 to 0.89 ) and for partners (Cronbach's alpha for the different measurement times ranged from 0.78 to 0.93 ).

QoL was measured with three subscales of the RAND36 [39]: physical functioning (ten items), social functioning (two items) and mental health (five items). To avoid statistical problems due to multiple comparisons, we chose these three subscales as a representation of overall QoL. The RAND-36 measures generic QoL. After recoding and transformation, scores on the subscales could range from 0 to 100 . Higher scores indicate a better QoL. Reliability of these scales was good to very good for patients (Cronbach's alpha for the different measurement times ranged from 0.67 to 0.90 ) and for partners (Cronbach's alpha for the different measurement times ranged from 0.75 to 0.92 ). The Dutch manual for the RAND-36 provides reference scores. These comprised the mean scores of a group of 691 nonselected men and 372 nonselected women from a random representative sample of persons aged 18 years and older from the population register of a municipality in the north of The Netherlands (number of inhabitants $=108,000$ ). The mean age of the persons in the total random sample was 44.1 years (range 18-89 years) [39].

\section{Statistical analyses}

The database consisted of matched pairs of patients and partners, making analyses on pair level possible. Paired $t$ tests and chi-square test were performed to examine differences in sociodemographics between patients and partners. Wilcoxon signed rank test (because of small sample size) and correlations were computed to examine differences and relationships in SRS and QoL between patients and partners. Independent $t$ tests were performed for having children (yes or no) with SRS and QoL. Pearson's product moment correlations were calculated to examine the relationship between duration of the relationship and patients and partners' SRS and QoL. Repeated measures analysis of variance (ANOVA) was used to examine change over time in functioning. Pearson's product moment correlations were calculated to examine relationships between the functioning of patient and that of the partner and between measurement times. Strong correlation coefficients $(>0.50)$ indicate consistency between measurement times and stable responses between earlier and later levels of functioning. Independent $t$ tests were performed to compare QoL of patients and partners with those of a reference group of men and women.

\section{Results}

Sociodemographic and treatment-related variables

Sociodemographic and treatment related variables are reported in Table 1. Patients were older than partners ( $t=$ $-3.1, p<0.01)$. The mean time couples had been together was 5.7 years. Eighteen patients were employed for wages and 1 was a student, whereas 11 partners were employed for wages, 4 were home-keepers and the remaining 4 partners were students (chi-square $=19.0, p=0.04$ ). Of the 21 couples, 5 had children and 14 did not. After chemotherapy was completed (at T2), all patients were restaged. Patients without biochemical or radiological abnormalities were considered to have reached complete remission $(n=8)$. In case of proven residual disease, a resection of residual retroperitoneal tumor mass (RRRTM) was performed. Eleven patients underwent this surgery and were considered to be in complete remission afterward. 
Table 1 Descriptives of sociodemographic and treatment-related variables

\begin{tabular}{|c|c|c|c|c|}
\hline & \multicolumn{2}{|l|}{ Patient } & \multicolumn{2}{|l|}{ Partner } \\
\hline & Mean & $\mathrm{SD}$ & Mean & SD \\
\hline Age $(\text { years })^{b}$ & 31.6 & 6.6 & 28.9 & 7.6 \\
\hline Range & $19.9-43.5$ & & $19.8-44.7$ & \\
\hline Duration relationship (years) & 5.7 & 6.3 & & \\
\hline Range & $1-22$ & & & \\
\hline \multirow[t]{2}{*}{ Education level } & 3.6 & 1.4 & 4.0 & 1.6 \\
\hline & $\mathrm{N}$ & $\%$ & $\mathrm{~N}$ & $\%$ \\
\hline \multicolumn{5}{|l|}{ Employment status ${ }^{\mathrm{b}}$} \\
\hline Employed for wages & 18 & 95 & 11 & 58 \\
\hline Student & 1 & 5 & 4 & 21 \\
\hline Housewife & & & 4 & 21 \\
\hline \multicolumn{5}{|l|}{ Children } \\
\hline Yes & 5 & 26 & & \\
\hline No & 14 & 74 & & \\
\hline \multicolumn{5}{|l|}{ RRRTM + } \\
\hline Yes & 11 & 58 & & \\
\hline No & 8 & 42 & & \\
\hline
\end{tabular}

$R R R T M$ Resection of residual retroperitoneal tumor mass ${ }_{p}^{\mathrm{a}}<0.01$
${ }_{p}^{\mathrm{b}}<0.05$

None of the 19 patients experienced a relapse during follow-up (up to T3).

Patients' and partners' SRS and QoL

At T1, SRS of patients were moderately strongly and negatively related to those of partners $(r=-0.48, p<0.05)$. At T2, social functioning of patients was moderately strongly and positively related to that of partners $(r=0.53$, $p<0.05)$. At the three measurement times all other correlations between patients' SRS and QoL and those of partners were low to moderate, ranging from $r=0.04$ to 0.34 , and not statistically significant. At T1, in two couples, both patient and partner experienced SRS above the cut-off point. At T2 and T3 there were no couples in which both patient and partner experienced SRS above the cut-off point. Wilcoxon tests showed only one significant difference between patients and partners' functioning. At $\mathrm{T} 2$, patients reported a lower level of physical functioning than did partners $(Z=-2.6, p<0.01)$.

Independent $t$ tests did not show a significant relationship between having children and SRS for patients at all measurement times, and for partners at T1 and T2. At T3 partners with children reported higher levels of SRS than partners who did not have children $(t=2.6, p=0.018)$. The presence of children was unrelated to patients' and partners' QoL at all measurement times. The duration of the relationship was not significantly related to the patients' or partner's SRS or QoL at all measurement times and relationships were absent to very weak.

The course of SRS and QoL over time in patients and partners

Repeated measures ANOVA showed that the SRS of patients fluctuated according to a quadratic trend: The highest level was reported at $\mathrm{T} 1$ and after a decrease at T2, the level was increased again somewhat at T3. Earlier levels of SRS in patients were highly positively related to later levels (Table 2). At T1, five of the patients (26\%) reported stress response levels above the cut-off point; at T2, two patients (11\%); and at T3, three patients $(16 \%)$. Two patients reported clinically elevated levels of stress response levels at all measurement times. For partners the level of SRS declined, via a linear trend. Partners' reports of stress response levels were moderately strongly related between T1 and T2, strongly between T2 and T3, and the relationship between $\mathrm{T} 1$ and $\mathrm{T} 3$ was weak (Table 2). At T1, ten of the partners $(53 \%)$ reported stress response levels above the cut-off point, at T2, six (32\%), and at T3, two $(10.5 \%)$. One partner reported clinically elevated levels of stress response levels at all measurement times.

Lower physical functioning was reported by patients at $\mathrm{T} 2$ compared to $\mathrm{T} 1$, but physical functioning returned to baseline level at T3. Earlier levels of physical functioning in patients were not significantly related to later levels, and correlations were low. A decline in social functioning of patients was also found at T2 compared to T1, but higher social functioning than at baseline was found at T3. Social functioning of patients at T1 was positively and strongly related to functioning at $\mathrm{T} 2$, but the relationships between T2-T3 and T1-T3 were low to moderate. Mental health of patients improved over time. Mental health at T1 was positively and strongly related to levels at $\mathrm{T} 2$, and weakly to levels at T3. The relationship between mental health at $\mathrm{T} 2$ and $\mathrm{T} 3$ was moderately strong.

For partners, no significant time effects were found for physical functioning and mental health. Earlier levels of physical functioning and mental health of partners were highly and positively related to later levels. Social functioning of partners improved over the year and was highly positively related between $\mathrm{T} 1$ and $\mathrm{T} 2$ and between $\mathrm{T} 1$ and T3. The relationship between $\mathrm{T} 2$ and $\mathrm{T} 3$ was moderately strong. (Table 2 ).

QoL of patients and partners compared to that of a reference group of men and women

At T1, patients $(t=-3.4, p<0.01)$ and partners $(t=-2.1$, $p<0.05$ ) reported better physical functioning than the reference groups. Patients $(t=2.3, p<0.05)$ and partners $(t=2.9, p<0.01)$ reported worse social functioning than the 
reference groups at $\mathrm{T} 1$, and patients $(t=2.2, p<0.05)$ reported worse mental health at T1. At T2, patients reported worse physical functioning than the reference group of men $(t=2.6, p<0.02)$ but partners reported better physical functioning than the reference group of women ( $t=$ $-2.2, p<0.05)$. Patients also reported worse social functioning than the reference men at T2 $(t=3.3, p<0.01)$. No differences were found between the patients' and partners' mental health and the norm groups at T2. Only one significant difference was found at T3: Patients reported better physical functioning than men in the reference group $(t=-2.6, p<0.02)$ (Table 2).

\section{Discussion}

The present study was the first to prospectively and longitudinally examine psychosocial functioning in both testicular cancer patients and their partners. We focused on SRS and QoL (physical functioning, social functioning, and mental health) after orchiectomy but before the start of chemotherapy, immediately after completion of chemotherapy, and 9 months later (1 year follow-up).

SRS in couples were most salient before the start of chemotherapy. Twenty-six percent of patients reported clinically elevated SRS at this time, a number comparable to the $30 \%$ of patients with clinically elevated distress found in a recent study on testicular cancer patients [23]. A review of stress response syndromes in adult cancer populations showed that the incidence of clinically elevated SRS ranged from 3 to $4 \%$ in patients recently diagnosed with early stage cancer [34]. The majority of these studies used the same questionnaire for measuring SRS as we did. The same review identified younger age, greater proximity to diagnosis, more advanced disease, and greater treatment intensity as risk factors for a higher level of SRS. The much higher percentage found in our study at the first measurement time may be explained by the prevalence of these four risk factors in our patient group.

Not only did patients appear distressed, but also almost twice as many of the partners compared to patients reported clinically elevated levels of SRS. Female sex was found to correlate with greater stress response symptomatology in cancer populations [34]. Of course, these spouses are not patients themselves, but they obviously face cancer-related fears and worries as well. Our results affirm earlier findings that female spouses of cancer patients are vulnerable to distress, and often report higher levels of distress compared to their male counterparts $[20,21,40-42]$. It was also found that partners who had children experienced more SRS a year after diagnosis compared to partners without children. This higher level of distress might also be a result of caregiving tasks that are often the domain of female partners.

SRS in couples decreased after completion of chemotherapy. One year after diagnosis, stress response levels in patients rose slightly, but they continued to decrease in partners. These patterns suggest that the period before chemotherapy commences is most stressful, and that recovery seems to occur within a year. At the time of the first measurement the responses of the couples seem to be colored by the fact that they had recently learned the diagnosis, and the outcome of treatment remained uncertain. Concerns of couples about side effects of chemotherapy such as nausea, the possibility of immunodeficiency, and hair loss may contribute to distress. Partners also have caregiving tasks that can exacerbate their distress [22]. All couples in this study received

Table 2 SRS and QoL of patients and partners

\begin{tabular}{|c|c|c|c|c|c|c|c|c|c|c|c|c|c|}
\hline & & \multirow{2}{*}{$\begin{array}{l}\mathrm{T} 1 \\
\text { Mean (SD) }\end{array}$} & \multirow{2}{*}{$\begin{array}{l}\mathrm{T} 2 \\
\text { Mean (SD) }\end{array}$} & \multirow{2}{*}{$\begin{array}{l}\text { T3 } \\
\text { Mean (SD) }\end{array}$} & \multirow{2}{*}{$\begin{array}{l}\text { Reference group } \\
\text { Mean (SD) }\end{array}$} & \multicolumn{2}{|c|}{$\begin{array}{l}\text { Repeated } \\
\text { measures } \\
\text { ANOVA }\end{array}$} & \multicolumn{2}{|c|}{$\mathrm{T} 1-\mathrm{T} 2$} & \multicolumn{2}{|c|}{$\mathrm{T} 2-\mathrm{T} 3$} & \multicolumn{2}{|c|}{$\mathrm{T} 1-\mathrm{T} 3$} \\
\hline & & & & & & $F$ & $p$ & $r$ & $p$ & $r$ & $p$ & $r$ & $p$ \\
\hline \multirow[t]{2}{*}{ Stress response symptoms } & Patient & $18.1(13.0)$ & $10.2(10.7)$ & $12.3(9.9)$ & & 7.9 & 0.012 & 0.65 & 0.002 & 0.71 & 0.001 & 0.70 & 0.001 \\
\hline & Partner & $25.8(9.3)$ & $15.2(12.6)$ & $12.1(12.4)$ & & 17.7 & 0.001 & 0.41 & ns & 0.64 & 0.003 & 0.16 & ns \\
\hline \multirow[t]{2}{*}{ Physical functioning } & Patient & $93.4(10.8)$ & $70.5(23.4)$ & $92.6(13.3)$ & $84.5(22.3)^{\mathrm{a}, \mathrm{b}, \mathrm{c}}$ & 21.4 & 0.001 & 0.28 & ns & 0.38 & ns & 0.20 & $\mathrm{~ns}$ \\
\hline & Partner & $90.2(19.0)$ & $90.8(19.0)$ & $89.7(19.9)$ & $80.7(23.6)^{\mathrm{b}, \mathrm{d}}$ & 0.19 & ns & 0.79 & 0.001 & 0.80 & 0.001 & 0.97 & 0.001 \\
\hline \multirow[t]{2}{*}{ Social functioning } & Patient & $77.6(19.7)$ & $71.1(22.8)$ & $90.8(13.1)$ & $88.4(19.6)^{\mathrm{d}, \mathrm{e}}$ & 9.0 & 0.008 & 0.61 & 0.009 & 0.19 & ns & 0.17 & $\mathrm{~ns}$ \\
\hline & Partner & $72.1(20.2)$ & $77.6(20.7)^{f}$ & $84.5(16.5)$ & $86.1(20.9)^{\mathrm{a}}$ & 12.9 & 0.002 & 0.60 & 0.007 & 0.37 & ns & 0.68 & 0.001 \\
\hline \multirow[t]{2}{*}{ Mental health } & Patient & $68.2(22.3)$ & 77.5 (11.9) & $81.9(13.4)$ & $79.4(17.3)^{\mathrm{d}}$ & 6.7 & 0.019 & 0.55 & 0.017 & 0.33 & ns & 0.23 & $\mathrm{~ns}$ \\
\hline & Partner & $69.1(13.6)$ & $71.2(15.6)$ & $74.3(15.1)$ & 75.5 (18.9) & 2.6 & ns & 0.72 & 0.001 & 0.64 & 0.004 & 0.52 & 0.023 \\
\hline
\end{tabular}

${ }_{\mathrm{a}}^{\mathrm{a}} p<0.01$ (independent $t$ test T1 and reference group)

${ }_{p}^{\mathrm{b}}<0.05$ (independent $t$ test T2 and reference group)

$c<0.05$ (independent $t$ test T3 and reference group)

${ }_{p<0.05}$ (independent $t$ test T1 and reference group)

${ }_{p} p<0.01$ (independent $t$ test T2 and reference group)

${ }^{\mathrm{f}} p<0.01$ (Wilcoxon test patients and spouses) 
positive news about the results of treatment, and 1 year after diagnosis none of the patients had experienced a relapse of disease. Couples seemed to have recovered from this major life event over the year, possibly as a consequence of the success of treatment reducing insecurity about outcome.

An interesting finding was that before commencement of chemotherapy, the level of SRS of patient and partner was inversely related. When one spouse was reporting more SRS, the other reported less. This might be a psychological mechanism through which spouses want to protect one another from their own distress, a finding reported before in studies on couples facing cancer [40]. Another possible interpretation might be that patients who expressed very low levels of distress were using denial, avoidance, or other repressive psychological mechanisms while their partners carried the psychological burden of stress. A patient who expresses high distress may also allow his spouse to assume a stronger supportive role, and thus reduce her expression of stress.

In line with the medical trajectory, physical functioning of patients was worst after completion of chemotherapy. As a consequence of chemotherapy, many patients still experience adverse side effects, including fatigue and a sense of physical exhaustion. It is surprising to note that physical functioning of patients was better than that of the reference group before start of chemotherapy and 1 year later. The first measurement occurred shortly after removal of the affected testicle, and patients may have experienced physical relief after the initiation of treatment. It may also be that age contributed to the difference found between the patient group and the reference group. Younger age is associated with better physical functioning [39], and the mean age of the patients in this study was somewhat more than 10 years lower than that of the reference group. There may have been other differences from the reference group as well, such as physical activity and SES. Partners' physical functioning did not change over the year but they also experienced better physical functioning than the reference group before and after chemotherapy. In an earlier cross-sectional study we found that partners of men who survived testicular cancer between 1-20 years reported better physical functioning than a reference group of women, even years after diagnosis [30]. Partners of testicular cancer patients may have changed the evaluation of their own health in a positive way after witnessing the diagnosis and treatment of a life-threatening illness.

In patients, social functioning was worst immediately after completion of chemotherapy, and in spouses before start of chemotherapy. Before start of chemotherapy, both partners reported worse social functioning compared to the reference groups. Before chemotherapy starts, couples are probably overwhelmed by the implications of a cancer diagnosis and focus more on the treatment to come rather than on being socially active as usual. As a consequence of chemotherapy, patients may still suffer from negative side effects like fatigue and impaired physical functioning, which in turn may affect their social functioning. Social functioning in patients and partners was positively related after completion of chemotherapy, meaning that when one partner experienced better social functioning the other also did. Couples had comparable social functioning to that of the reference groups 1 year after diagnosis; they seem to have returned to their usual social activities. This finding is in line with studies on testicular cancer survivors that show little or no change in social contacts and work activities [6, 43].

Mental health of patients improved over the year. It was poorer than that of men in the reference group but only before start of chemotherapy. Mental health of partners was comparable throughout the year and to that of a reference group of women, despite the high level of SRS they reported before start of chemotherapy. SRS apparently are a different expression of mental functioning and may be encapsulated or separated out.

It appeared that functioning in couples facing testicular cancer was not similar in patients and partners. Testicular cancer patients showed u-shaped trajectories of SRS, physical functioning, and social functioning. This pattern seemingly followed the medical trajectory they had undergone and was found before in a large group of testicular cancer patients [24]. Mental health of patients improved over the year. Spouses reported a decline in SRS and an improvement in social functioning, but no change in physical functioning or mental health over the year. Differences between patients and partners were also noticeable in stability of functioning. In patients, earlier levels of SRS were strongly predictive of later levels while less individual stability was found with regard to physical and social functioning and to mental health. Partners reported less individual stability in SRS over time, although individual stability was found between $\mathrm{T} 2$ and T3. However, partners were individually highly consistent in their reports of physical functioning and somewhat less strong in mental health and social functioning. In addition, correlations between the functioning of patients and partners were moderate to very low. We also found that at the second and third measurement time, there were no couples in which both the patient and the partner reported clinically elevated levels of SRS. This finding confirms the lack of correspondence in functioning between patient and partner.

These findings support recent studies that found different adjustment patterns for patients and partners, and a lack of correspondence in functioning $[19,20]$. Research is needed to examine if these different reaction patterns to a cancer diagnosis affect the marital relationship.

This study has some limitations. First, the possibility of including couples was limited because testicular cancer has a low incidence, and because of the young age of patients at diagnosis, part of this group will not yet have established a steady relationship. Second, no information was available 
on the functioning of couples who declined to participate. They may have been those who were functioning best or worst, thus biasing the results in either direction. Third, because of the limited sample size, variables that measure more in depth relationship aspects like marital satisfaction were not included in this study. In a previous retrospective study on testicular cancer, factors identified as important for couple adjustment like good communication, spousal support, and marital satisfaction all appeared to facilitate better functioning [32]. These moderating factors in adjustment of both patient and spouse deserve to be studied prospectively in the future.

In summary, this study was the first longitudinal prospective exploration of functioning in couples facing testicular cancer during the first year after the diagnosis. Patients confronted with disseminated testicular cancer and their partners reacted differently to this stressor. Clinically elevated stress response levels were present in one third of patients and half of the partners before start of chemotherapy. Patients reported worst mental health before start of chemotherapy, and worst physical and social functioning immediately after completion of chemotherapy. Partners reported an improvement in social functioning, and no change in physical functioning and mental health over the year. QoL of patients and partners was comparable to that of the reference groups a year after start of chemotherapy, patients even reported better physical functioning at that time. These findings support earlier retrospective studies in testicular cancer survivors and their spouses that also reported few long-term effects in psychosocial functioning in the group overall, but that identified a small group that remains distressed [16, 31, 32]. Little correspondence was found in the functioning of the partners. Findings should be regarded as preliminary, as the study sample was limited in size. However, clinicians can be reassured that the effect of disseminated testicular cancer on the QoL of patients and their partners seems to be temporary, although a minority does seem to need clinical attention for SRS.

Acknowledgements This research was supported by a grant from the Dutch Cancer Society, no. RUG 99-2130, and the Lance Armstrong Foundation.

\section{References}

1. Visser O, Siesling S, Van Dijck JAAM (2005) Incidence of cancer in The Netherlands 1999/2000. Eleventh report of The Netherlands Cancer Registry. Association of Comprehensive Cancer Centres, 2003. Association of Comprehensive Cancer Centres, pp 27-24

2. Shelley MD, Burgon K, Mason MD (2002) Treatment of testicular germ-cell cancer: a cochrane evidence-based systematic review. Cancer Treat Rev 28:237-253

3. Jones RH, Vasey PA (2003) Part II: testicular cancer - management of advanced disease. Lancet Oncol 4: 738-747

4. Vaughn DJ, Gignac GA, Meadows AT (2002) Long-term medical care of testicular cancer survivors. Ann Intern Med 136(6):463-470

5. Sonneveld DJA, Hoekstra HJ, van der Graaf WT, Sluiter WJ, Mulder NH, Willemse PHB, Koops HS, Sleijfer DT (2001) Improved long term survival of patients with metastatic nonseminomatous testicular germ cell carcinoma in relation to prognostic classification systems during the cisplatin era. Cancer 91(7):1304-1315

6. Dahl AA, Mykletun A, Fossa SD (2005) Quality of life in survivors of testicular cancer. Urol Oncol 23 (13):193-200
7. Fossa SD, Dahl AA, Loge JH (2003) Fatigue, anxiety, and depression in long-term survivors of testicular cancer. J Clin Oncol 21(7):1249-1254

8. Iconomou G, Mega V, Koutras A, Iconomou AV, Kalofonos HP (2004) prospective assessment of emotional distress, cognitive function, and quality of life in patients with cancer treated with chemotherapy. Cancer 101 (2):404-411

9. Knobf MT, Pasacreta JV, Valentine A, McCorkle R (1998) Chemotherapy, hormonal therapy, and immunotherapy. In: Holland JC (ed) Psycho-oncology. Oxford University Press, New York, pp 277-288

10. Vidrine DJ, Gritz ER (2003) Psychosocial outcomes after testicular cancer treatment. In: Steele GD Jr, Phillips TL, Chabner BA, Gansler TS (eds) Germ cell tumors, American Cancer Society Atlas of Clinical Oncology. BC Decker, Hamilton, London, pp 295-305

11. Kim Y, Duberstein PR, Sörensen S, Larson MR (2005) Levels of depressive symptoms in spouses of people with lung cancer: effects of personality, social support and caregiver burden. Psychosomatics 46(2):123-130

12. Hagedoorn M, Sanderman R, Buunk BP, Wobbes T (2002) Failing in spousal caregiving: the 'identity-relevant stress' hypothesis to explain sex differences in caregiver distress. Br J Health Psychol $7: 481-494$
13. Nijboer C, Triemstra M, Tempelaar R, Sanderman R, Van den Bos GAM (1999) Determinants of caregiving experiences and mental health of partners of cancer patients. Cancer 86(4): 577-588

14. Schover LR, von Eschenbach AC (1985) Sexual and marital relationships after treatment for nonseminomatous testicular cancer. Urology 25(3): 251-255

15. Schover LR, Gonzales M, von Eschenbach AC (1986) Sexual and marital relationships after radiotherapy for seminoma. Urology 27(2):117-123

16. Gritz ER, Wellisch DK, Wang HJ, Siau J, Landsverk JA, Cosgrove MD (1989) Long-term effects of testicular cancer on sexual functioning in married couples. Cancer 64(7):1560-1567

17. Baider L, Koch U, Esacson R, De Nour AK (1998) Prospective study of cancer patients and their spouses: the weakness of marital strength. Psychooncology 7(1):49-56

18. Keller M, Henrich G, Sellschopp A, Beutel M (1996) Between distress and support: spouses of cancer patients. In: Baider L, Cooper CL, Kaplan De-Nour A (eds) Cancer and the family. Wiley, Chichester, England, pp 187-223

19. Northouse LL, Mood D, Templin T, Mellon S, George T (2000) Couples' patterns of adjustment to colon cancer. Soc Sci Med 50:271-284 
20. Tuinstra J, Hagedoorn M, Van Sonderen E, Ranchor AV, Van den Bos GAM, Nijboer C, Sanderman R (2004) Psychological distress in couples dealing with colorectal cancer: gender and role differences and intracouple correspondence. Br J Health Psychol 9:465-478

21. Hagedoorn M, Tuinstra J (2003) Living together with cancer. The emotional well-being of patients and their partners. Gedrag Gezond (Behavior and Health) 30(3):193-203

22. Matthews AB (2003) Role and gender differences in cancer-related distress: a comparison of survivor and caregiver self-reports. Oncol Nurs Forum 30 (3):493-499

23. Trask PC, Paterson AG, Fardig J, Smith DC (2003) Course of distress and quality of life in testicular cancer patients before, during, and after chemotherapy: results of a pilot study. Psychooncology 12:814-820

24. Fossa SD, de Wit R, Trevor Roberts J, Wilkinson PM, de Mulder PHM, Mead GM, Cook P, de Prijck L, Stenning S, Aaronson NK, Bottomley A, Collette L (2003) Quality of life in good prognosis patients with metastatic germ cell cancer: a prospective study of the European Organization for Research and Treatment of Cancer Genitourinary Group/Medical Research Council Testicular Cancer Study Group (30941/ TE20). J Clin Oncol 21(6):1107-1118

25. Holzik MFL, Rapley EA, Hoekstra HJ, Sleijfer DT, Nolte IM, Sijmons RH (2004) Genetic predisposition to testicular germ-cell tumours. Lancet Oncol 5 (6):363-371
26. Jonker-Pool G, van de Wiel HB, Hoekstra HJ, Sleijfer DT, van Driel MF, van Basten JP, Schraffordt Koops HS (2001) Sexual functioning after treatment for testicular cancer-review and meta-analysis of 36 empirical studies between 1975-2000. Arch Sex Behav 30(1):55-74

27. Nuver J, Smit AJ, Postma A, Sleijfer DT, Gietema JA (2002) The metabolic syndrome in long-term cancer survivors, an important target for secondary preventive measures. Cancer Treat Rev 28(4):195-214

28. van Basten JP (1999) The sexual sequelae of testicular cancer. Dissertation Rijksuniversiteit Groningen 1999. Available at http://irs.ub.rug.nl/ ppn/181455765

29. Fleer J, Hoekstra HJ, Sleijfer DT, Tuinman MA, Klip EC, HoekstraWeebers JEHM (2006) Quality of life of testicular cancer survivors and the relationship with sociodemographics, cancer-related variables and life events. Support Care Cancer 12(7):476-486

30. Tuinman MA, Fleer J, Hoekstra HJ, Sleijfer DT, Hoekstra-Weebers JEHM (2004) Quality of life and stress response symptoms in long-term and recent spouses of testicular cancer survivors. Eur J Cancer 40(11): 1696-1703

31. Gritz ER, Wellisch DK, Landsverk JA (1988) Psychosocial sequelae in longterm survivors of testicular cancer. J Psychosoc Oncol 6(3/4):41-63

32. Gritz ER, Wellisch DK, Siau J, Wang HJ (1990) Long-term effects of testicular cancer on marital relationships. Psychosomatics 31(3):301-312

33. Tuinman MA, Fleer J, Sleijfer DT, Hoekstra HJ, Hoekstra-Weebers JEHM (2005) Marital and sexual satisfaction in testicular cancer survivors and their spouses. Support Care Cancer 13 (7):540-548

34. Gurevich M, Devins GM, Rodin GM (2002) Stress response syndromes and cancer: conceptual and assessment issues. Psychosomatics 43(4):259-281
35. Horowitz M, Wilner N, Alvarez W (1979) Impact of event scale: a measure of subjective stress. Psychosom Med 41 (3):209-218

36. van der Ploeg E, Mooren TTM, Kleber RJ, van der Velden PG, Brom D (2004) Construct validation of the Dutch version of the impact of event scale. Psychol Assess 16(1):16-26

37. Sundin EC, Horowitz MJ (2002) Impact of event scale: psychometric properties. Br J Psychiatry 180(3): 205-209

38. Thewes B, Meiser B, Hickie IB (2001) Psychometric properties of the impact of event scale amongst women at increased risk for hereditary breast cancer. Psychooncology 10:459-468

39. van der Zee KI, Sanderman R (1993)

The measurement of generic health with the RAND-36. Northern Centre for Healthcare Research. Available at http://coo.med.rug.nl/nch

40. Manne S (1998) Cancer in the marital context: a review of the literature. Cancer Invest 16(3):188-202

41. Eton DT, Lepore SJ, Helgeson VS (2005) Psychological distress in spouses of men treated for early-stage prostate carcinoma. Cancer 103 (11):2412-2418

42. Rees J, Clarke MG, Waldron D, O'Boyle C, Ewings P, MacDonagh RP (2005) The measurement of response shift in patients with advanced prostate cancer and their partners. Health Qual Life Outcomes 3:21

43. Stoter G, Koopman A, Vendrik CPJ, Struyvenberg A, Sleyfer DT, Willemse PHB, Koops HS, Vanoosterom AT, Huinink WWT, Pinedo HM (1989) 10 -year survival and late sequelae in testicular cancer-patients treated with cisplatin, vinblastine, and bleomycin. J Clin Oncol 7(8):1099-1104 